\title{
High-resolution marine magnetic surveys for searching underwater cultural resources
}

\author{
Fabio Caratori Tontini $\left({ }^{1}\right)$, Cosmo Carmisciano $\left({ }^{1}\right)$, Marcello Ciminale $\left({ }^{2}\right)$, Marco Grassi $\left({ }^{3}\right)$, \\ Paolo Lusiani $\left({ }^{3}\right)$, Stefano Monti $\left({ }^{4}\right)$ and Paolo Stefanelli $\left({ }^{1}\right)$ \\ (') Istituto Nazionale di Geofisica e Vulcanologia, Sede di Portovenere, Fezzano (SP), Italy \\ $\left.{ }^{(}\right)$Dipartimento di Geologia e Geofisica, Università degli Studi di Bari, Italy \\ $\left(^{3}\right)$ Istituto Idrografico della Marina, Genova, Italy \\ $\left(^{4}\right)$ Comando Operativo Vertice Interforze, Ufficio GEO-METOC, Roma, Italy
}

\begin{abstract}
Recently two marine magnetic surveys, combined with the use of a multi-beam sonar (Kongsberg Marittime EM 300 multibeam: $30 \mathrm{KHz}$ frequency echosounder for hydrographic purposes; acoustic lobe composed of 128 beams able to cover a $150^{\circ}$ sector) a side-scan sonar (Simrad MS 992 dual-frequency sidescan sonar with echo sounder transducers $150 \mathrm{~Hz}$ and $330 \mathrm{KHz}$ ) and a Remote Operated Vehicle (ROV - a mobile tools used in environments which are too dangerous for humans), were executed in two sites respectively in the Ligurian Sea and the Asinara Gulf. The aim of these investigations was to test modern instrumentations and set new working procedures for searching underwater cultural resources. The collected and processed magnetic data yielded very satisfactory results: we detected submerged and buried features of cultural interest at both sites, at depths of $40 \mathrm{~m}$ and 400 m respectively.
\end{abstract}

Key words High-resolution marine magnetic surveys - marine archaeological search - ship-wreck amphorae

\section{Introduction}

The development and diffusion of marine geophysical investigations for searching underwater and buried archaeological features (i.e. Chahuan and Almeida, 1988; Quinn et al., 2000) are hindered by the complexity of the execution and the very high costs involved.

A recent scientific cooperation among some Italian research institutions and the Italian Navy has been crucial in overcoming these obstacles

Mailing address: Dr. Cosmo Carmisciano, Istituto Nazionale di Geofisica e Vulcanologia, via Pezzino Basso 2, 19020 Fezzano (SP), Italy; e-mail: carmisciano@ingv.it and it has allowed the implementation of an interesting research program on methodological, technical and practical aspects of the high-resolution marine magnetic surveys.

The present paper discusses subjects connected with the use of modern instrumentations and technologies and with appropriate data acquisition procedures. Then we describe two case histories performed at different depths and characterized by different submerged and buried targets.

In the first prospecting, a transverse gradiometer configuration was applied in order to detect high-frequency anomalies generated by a 20th-century shipwreck sunk at shallow depth (40 m). In the second case, the use of advanced technologies and appropriate data acquisition procedures were combined to execute a deep $(350 \mathrm{~m})$ magnetic survey resulting in fruitful finding of an extensive heap of Roman amphorae.

These satisfactory results establish an optimum starting-point to continue this interesting 
research in a branch of Marine Applied Geophysics which strongly requires considerable economic undertaking, a multi-disciplinary approach and the use of modern technologies.

\section{Aspects of the marine magnetic survey}

The high-definition study of a marine geomagnetic field structure involves the fundamental technical problems of establishing the following items:

i) the accuracy in positioning of the measurement points;

ii) the correct estimation of the geomagnetic time variation;

iii) high sensitivity instrumentations;

iv) the use of a low-noise magnetic vessel;

v) the survey procedure.

An high definition assessment of the crossover error (the differences in the measurements at the intersection of ship tracks) and an accurate positioning of the measurement points are of primary importance. These parameters are directly connected with the short-wavelength fields, as well as with the presence of possible magnetic sources lying on the seabed. The highly detailed positioning of the measurement points can be carried out by means of a DGPS (Differential Global Positioning System) or a GPS coded $P$, usually equipped on board of military ships. Currently, more innovative positioning techniques based on RTK (Real Time Kinematics) have being tested. This technique seems to be very successful, above all in the coastal sea area where it is possible to install a «base receiver» which communicates with the «rover receiver» placed on board; the distance between the base and rover receivers defines the «baseline». Once the base receiver has resolved the ambiguities correctly, the accuracy of each position computation is within a few $\mathrm{cm}$, depending on the antenna multipath rejection capability.

In order to make the geomagnetic field measurements independent from time variations, setting up a temporary geomagnetic observatory in the study area is particularly effective. The site selection is made through the coherence analysis (Parkinson and Jones, 1979).
The spatial stability of the observatory measurements, i.e. the evaluation of the coherence, is obtained by comparing one or more magnetograms produced by coastal base stations (Faggioni et al., 1997; Faggioni and Caratori Tontini, 2002).

During the surveys discussed herein, the geomagnetic observatories were equipped with a portable Geometrics G858 caesium magnetometer with a sensitivity of $0.05 \mathrm{nT}$ at a sampling rate of $10 \mathrm{~Hz}$.

The instrumentation used for collecting marine magnetic data was a Geometrics G-880 caesium magnetometer (sensitivity $0.05 \mathrm{nT}$ at a $0.1 \mathrm{~Hz}$ ) equipped with two sensors. Beside the standard arrangement (the use of one sensor only), two basic gradiometer sensor array configurations are possible: transverse horizontal or longitudinal (fig. 1). In the first configuration, a particular tow frame assembly holds the tow points of the magnetometers apart at a fixed distance $(2 \mathrm{~m})$. This frame consists of a triangular structure composed of fibreglass spars and aluminium couplings (fig. 2). A ballast fish provides the necessary weight to maintain the frame in a horizontal position, thereby avoiding the hydrodynamic «tilt». Due to the distance between the two sensors and to the hydrostatic sustenance of the whole structure, this configuration is particularly effective in shallow waters for high frequency anomalies. On the contrary, if deep waters and long wavelengths are involved, the longitudinal configuration is commonly adopted; in this case, the sensors are towed along the same line at a fixed distance one from the other, depending on the wavelength of the signal of interest. In both case the array is towed by a Kevlar coax cable which was digital data immune from shipboard noise. In order to facilitate handling, a single coax cable, supplied with a Telemetry Interface Unit, assure power supply, bidirectional communication and control for all towfish systems to be multiplexed down a single co-axial cable. The telemetry system employed a transmission frequency of $200 \mathrm{KHz}$ in order to obtain the best propagation with the lowest attenuation.

The sensors of this magnetometer are also equipped with a depth transducer, particularly useful in vertical gradient application or for quick- 

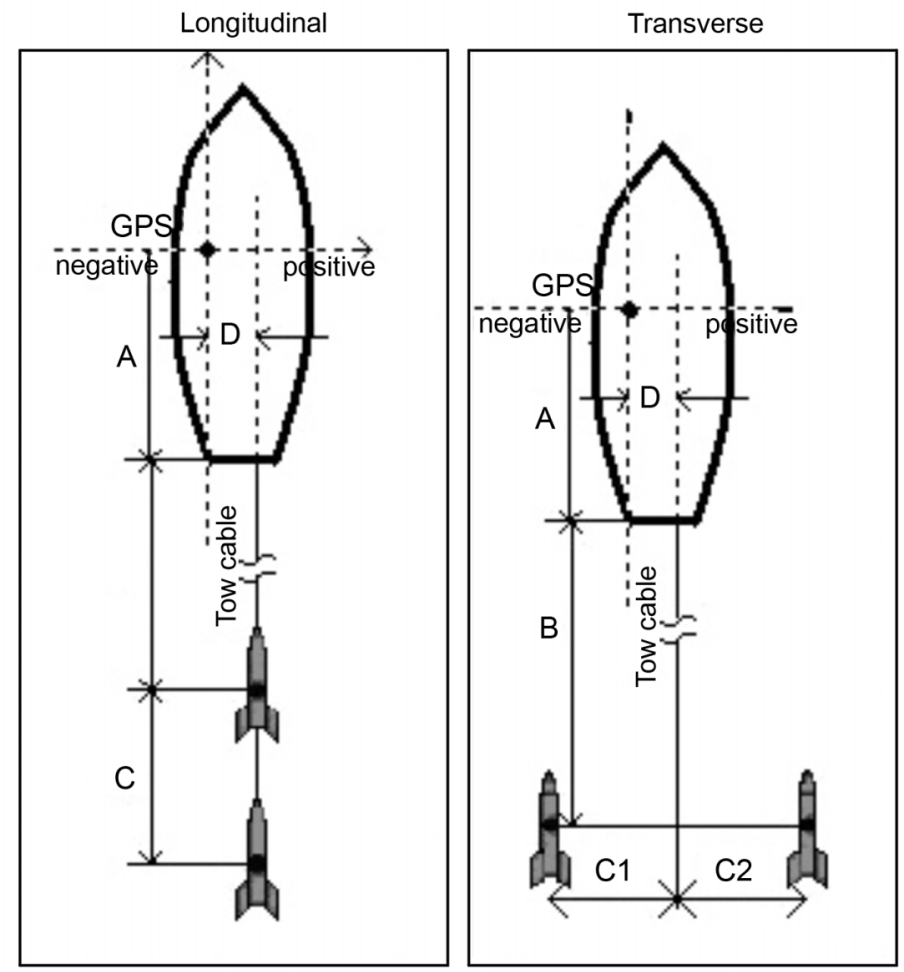

Fig. 1. The geometry of the two G880 sensors: transverse and longitudinal gradiometric scheme.

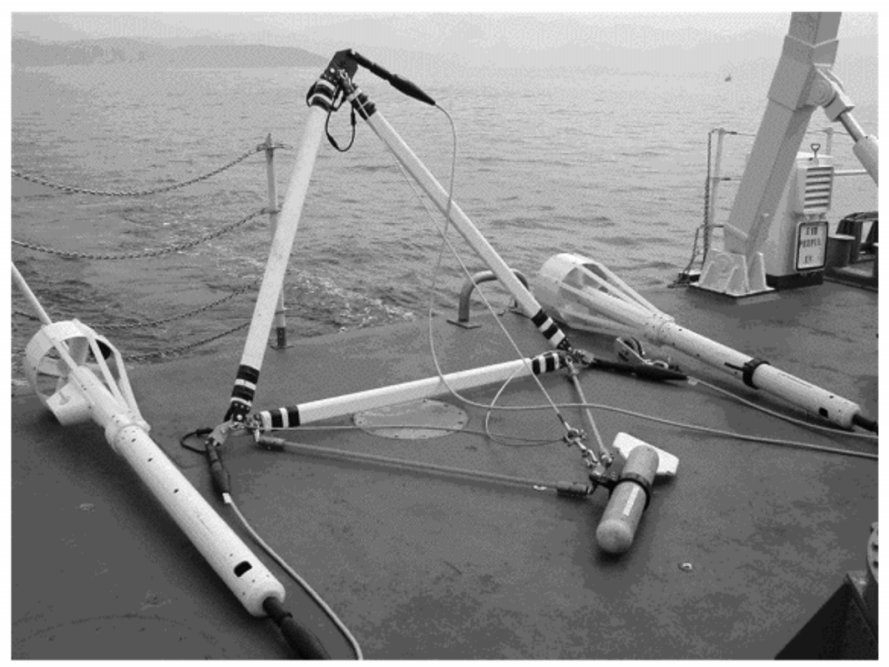

Fig. 2. Instrumentation used for the transverse gradiometric array; the two sensors, the ballast and the triangular frame are visible. 


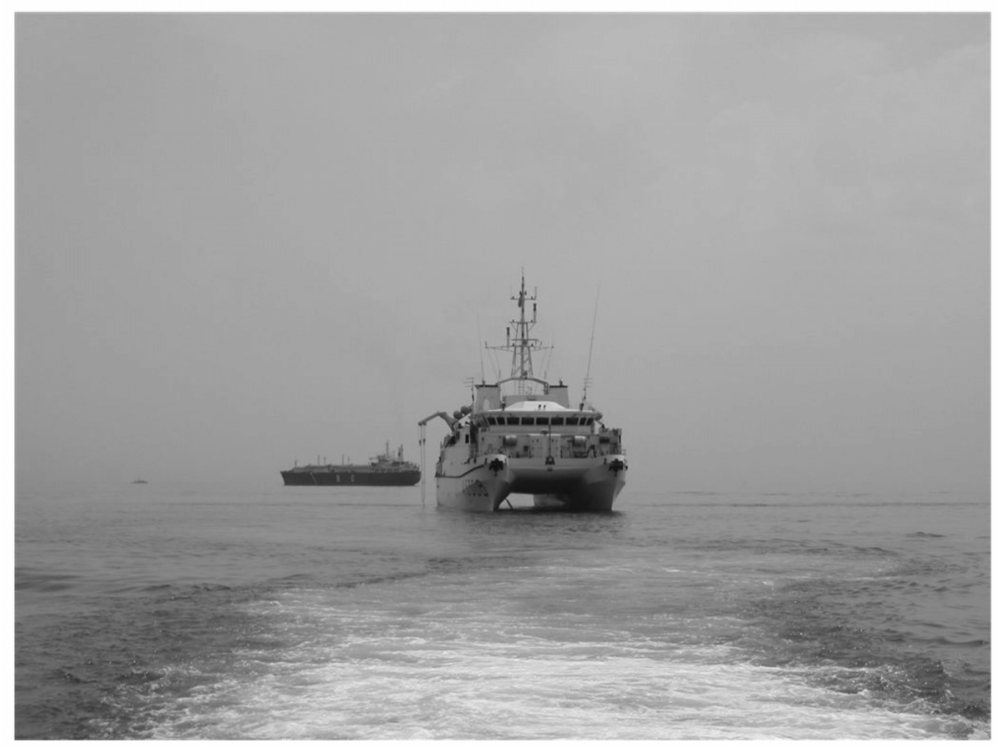

Fig. 3. Hydrographic ship Galatea.

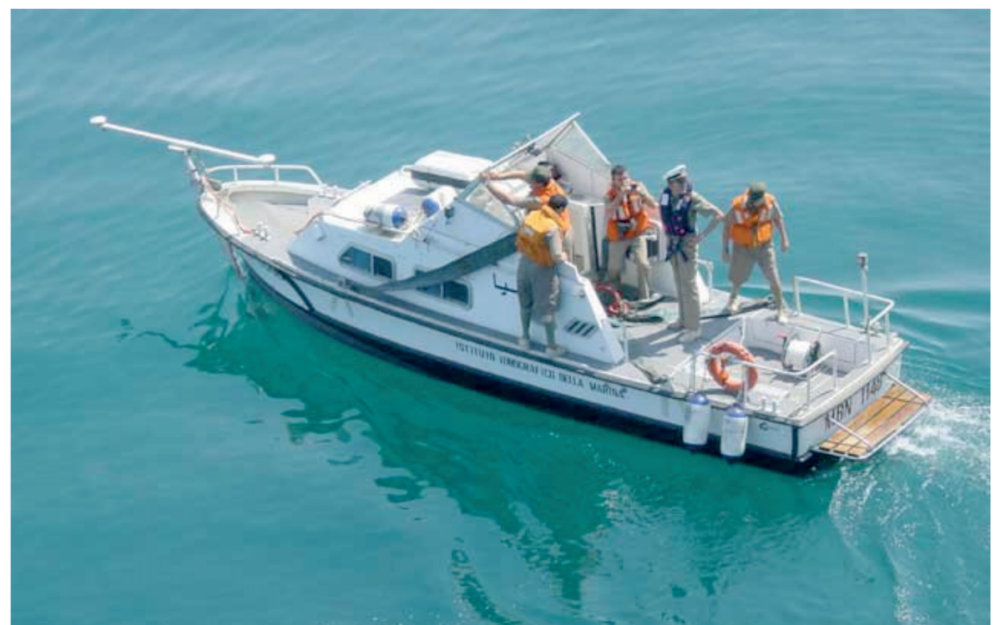

Fig. 4. Small hydrographical GRP boat.

connection integration to side-scan sonar systems to communicate the sensor depth on-line.

A low-noise magnetic vessel allows the use of a short tow cable. In January 2002, Interma- rine (an Italian naval shipyard, specializing in the design and manufacturing of fiber reinforced plastic marine crafts) delivered two new catamaran-type Hydrographic Survey Vessels 
to the Italian Navy: the Aretusa and the Galatea. Wholly built in composite materials, the vessels have a length of almost $40 \mathrm{~m}$, a width of $13 \mathrm{~m}$ and a 415 tons displacement. At present, they are the largest GRP (Glass Reinforced Plastic) catamarans in the world (fig. 3). Although these vessels may appear a little cumbersome, they are very useful especially if the survey is carried out far off the coastal area and lasts many days. A smaller more practical boat, carried on board the catamaran, may be employed to perform surveys in shallower waters, closer to the coast: this boat is a small hydrographical GRP boat, equipped with a hull-mounted echosounder, communication equipment, radio-positioning systems and computer for data acquisition (fig. 4).

In order to emphasize the dipolar geometry, typical of the geomagnetic artificial sources, the survey planning is organized by parallel profiles aligned along a south-north direction. The distance between the profiles and the sampling rate are chosen according to the characteristics and the depth of the submerged target, to- gether with the ship manoeuvre level. In the applications of this study, the profile separation ranged from $25 \mathrm{~m}$, in the first survey, to $100 \mathrm{~m}$, for the second one. In order to define the survey accuracy and to perform statistical leveling, some orthogonal control tie lines were also carried out. The high sampling rate of the magnetometer (10 data/s) combined with the maximum speed allowed to ensure the safety of the dropping sensor structure (5 knots) yields a maximum spatial sampling step of $25 \mathrm{~cm}$; this value is very satisfactory to describe the magnetic signal in detail.

\section{Case histories}

\subsection{Testing the gradiometer configuration: detection of a shipwreck}

In November 2002 a marine survey just off the shore of Scoglio Ferale (La Spezia, Italy) was performed using the Galatea vessel to test the effectiveness of the transverse gradiometer

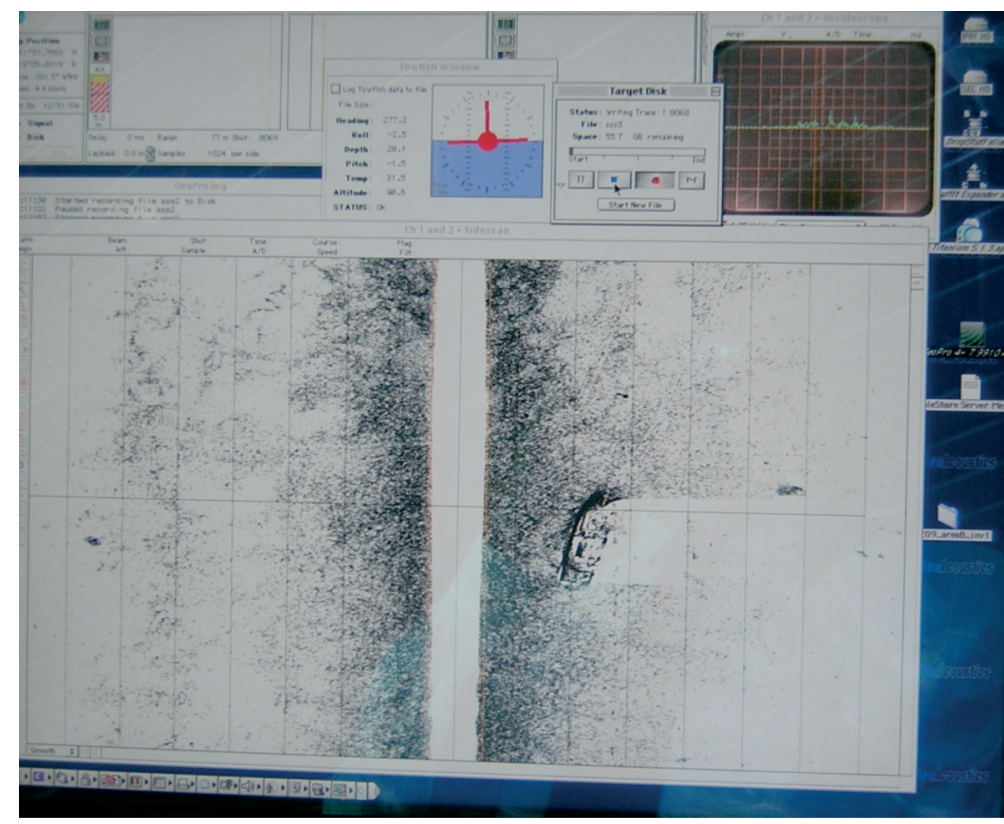

Fig. 5. Sonar images of the Equa wreck. 
configuration. In the surveyed area, a shipwreck is present at a depth of approximately 40 $m$ (fig. 5): it is the Italian armed cargo Equa which was sunk in 1944 (www.relitti.it). Ma- rine documents show that its original weight was about 300 tons, and that its structure was predominantly ferrous. Two sensors along parallel paths were used for collecting measure-

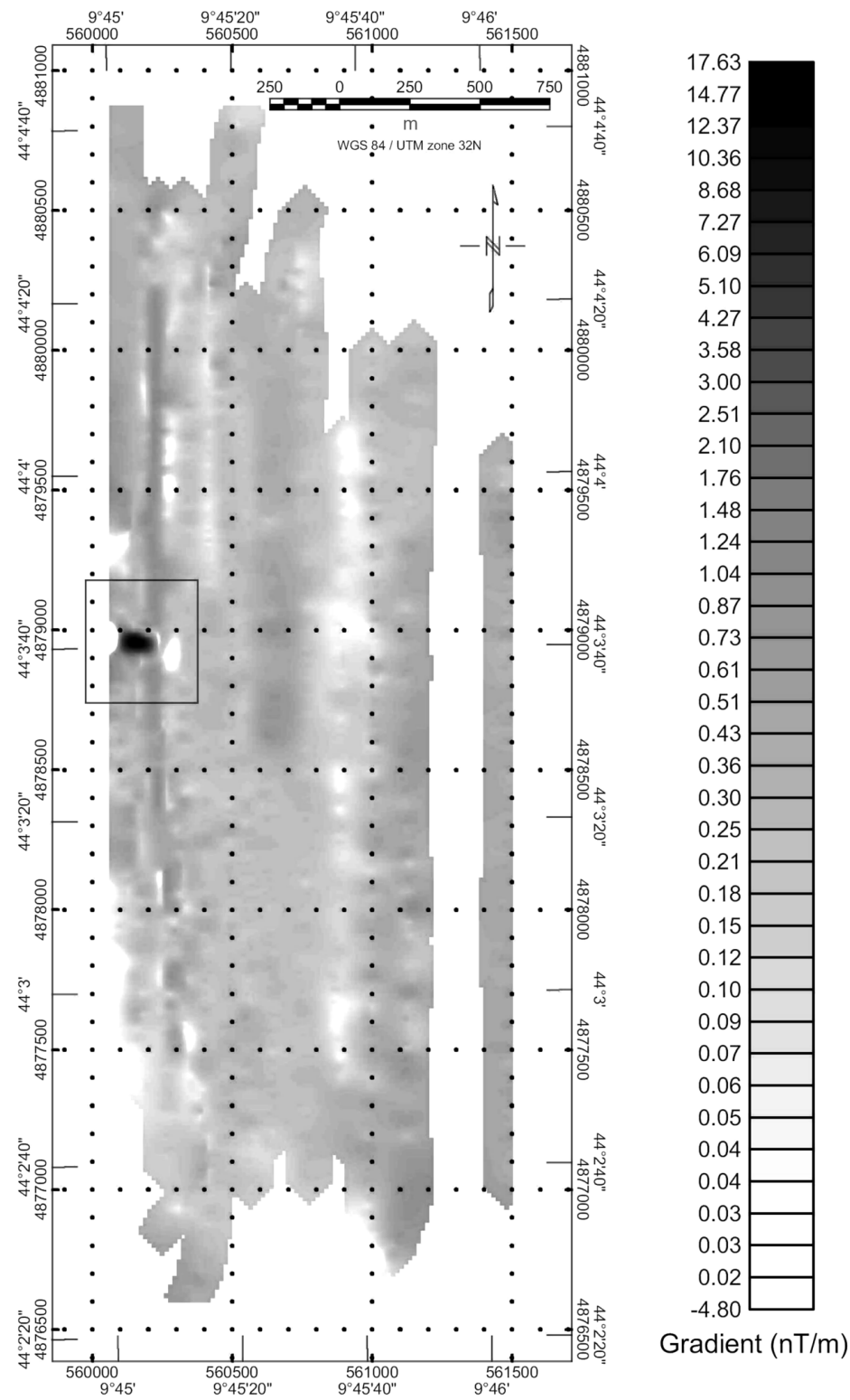

Fig. 6. Transverse horizontal gradiometric map of the offshore site of Scoglio Ferale (black dot on the map) underlying the ship line-paths; values and colour range [ -1.8 white, +12.7 black] nT/m. 
ments and to reduce the influence of time origin signal which could contaminate the measured values.

One intense high-frequency gradient anomalies can be observed in the centre of the map, corresponding to the location of the ship (fig. 6 ). The positioning of the measurement points can be carried out by means of a DGPS, sufficiently accurate for this test. It is important to note the decisive contribution given by the gradient field measurements to the correct interpretation of the magnetic sources: these measurements are approximately free of any time contaminations which sometimes may generate spurious signals, superimposing and disturbing the spatial anomalies.

\subsection{Technological improvement: the amphorae site}

In summer 2003, a detailed marine survey was performed in the Asinara Gulf (NW of Sardinia Island, Italy) using the Galatea vessel. According to historical evidence, some ships were sunk in this area during World War II. In this survey, the G880 magnetometer was used in standard configuration and quickly combined with a modern digital side scan sonar systems in order to measure the geomagnetic field as close as possible to the seabed. This investigation was also carried out to test a deep towed configuration which is believed to be very effective in archaeological applications in which

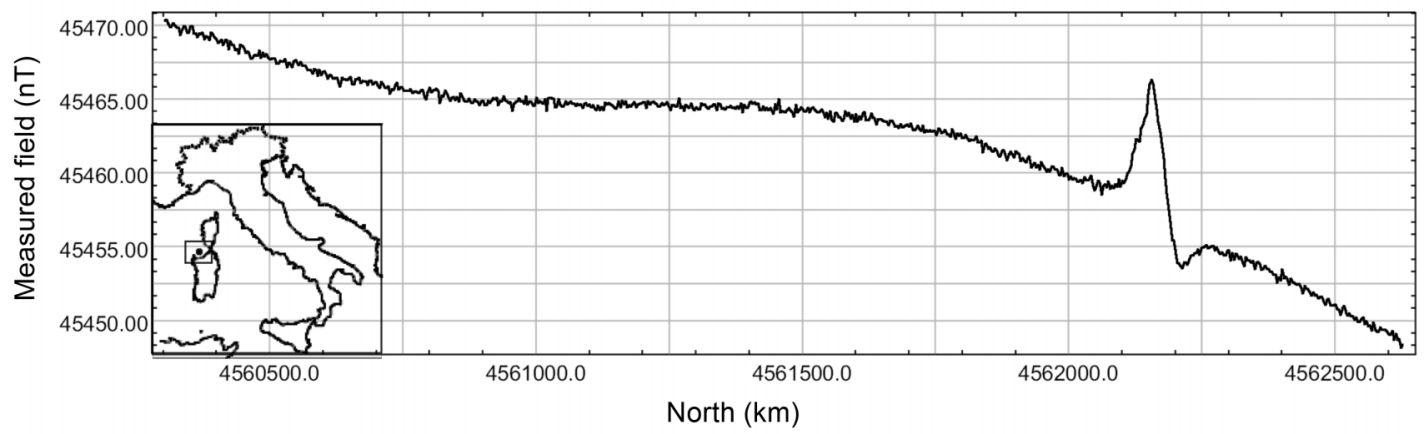

Fig. 7. Magnetic field along the significant profile recorded in the Asinara Gulf.
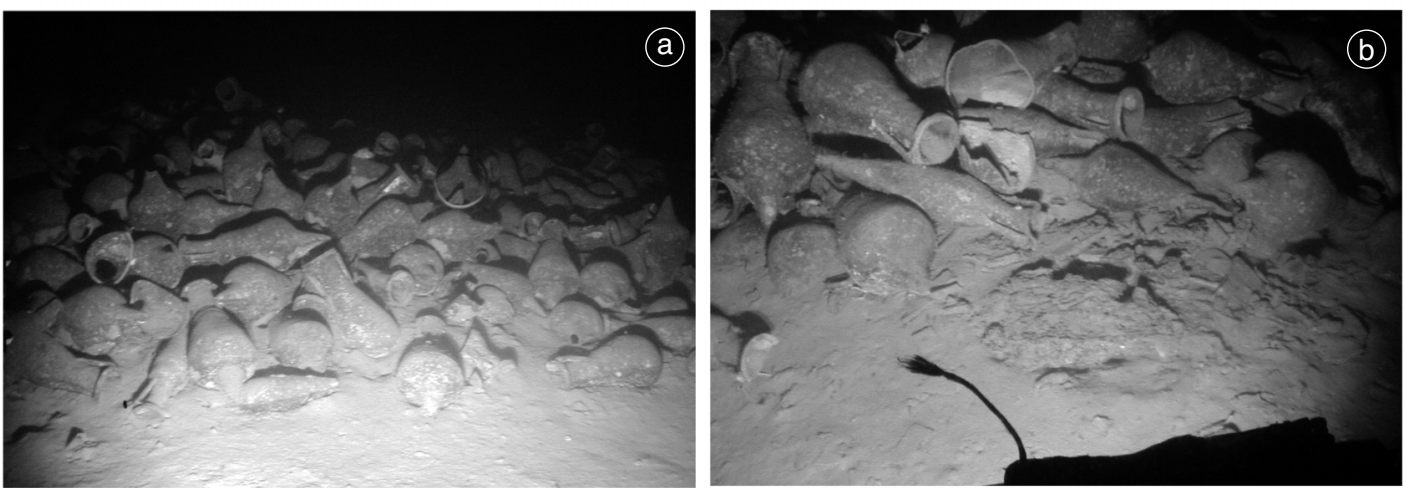

Fig. 8a,b. Two different views of the extensive submerged heap of Spanish amphorae. 
the targets of interest lie above the sea bottom. Indeed, the advanced instrumentation performance permits to use the magnetometer in deeper waters. In the case studied, the depth transducers are able to reach an operational depth of about $300 \mathrm{~m}$, but it is possible to upgrade its operational performance to a depth of $1000 \mathrm{~m}$.

The survey covered a series of $2 \times 2 \mathrm{~km} \mathrm{sec}-$ tors and, in each square, several parallel profiles were executed at a distance of $100 \mathrm{~m}$; in this case, the accurate positioning of the measurement points was obtained by means of a DGPS. The ship was maintained at a steady speed between 1 and $2 \mathrm{~km}$. This interval rate allowed the sensor, connected to the vessel by a $400 \mathrm{~m}$ Kevlar cable and a ballast of $100 \mathrm{~kg}$, to reach depths ranging between $[350,100] \mathrm{m}$. In this way, in water depths less than $400 \mathrm{~m}$, the magnetic measurements were collected at a level of about $35 \mathrm{~m}$ above the seabed.

Figure 7 shows the magnetic field measurements along a significant profile. A dipolar high frequency signal of about $14 \mathrm{nT}$ in amplitude is well isolated from the larger wavelength regional trend. In order to obtain the complete magnetic anomaly map, time variation reduction and regional trend removal were carried out by using a base station placed on the nearby coast and an appropriate second-degree polynomial in latitude and longitude (De Santis et al., 2003) respectively. Moreover, final adjustments of the data set were obtained through the procedures of statistical leveling and microleveling, to avoid residual intersection errors and line-path stretching along the surveyed profiles (Minty, 1991; Ferraccioli et al., 1998).

The subsequent visual inspection executed by means of an ROV has brought to light an extensive heap of amphorae (fig. 8a,b) at a depth of $400 \mathrm{~m}$.

Archaeologists seem to be very interested in this finding. The considerable depth at which this resource lies presents some problems with regard to its total or partial raising. However, at present, the study of its filmed images yields an important contribution to the reconstruction of the commercial courses between Spain and Italy during the Imperial Age (I, II century A.D.). In fact, the two types of amphorae discovered are of Spanish manufacture (more ex- actly from the Betica region, south of Spain) and were used to transport garum, a savoury fish sauce used in that period and highly appreciated in the city of Rome.

\section{Conclusions}

The marine magnetic survey for archaeological prospecting has been considered by developing technical and experimental aspects. The two cases reported demonstrated the high level of information that this type of investigation may obtain, concerning both the location of the sources (shallow or deep waters) and their magnetic origin. The obstacle represented by both the complexity of a marine investigation and by the high costs involved may be overcome by establishing a sound scientific cooperation between Institutions which offer scientific capacity, grants and modern instruments as was the case in the present investigations discussed.

\section{Acknowledgements}

We thank the reviewers M. Fedi and A. Pignatelli for their useful comments.

\section{REFERENCES}

Chahuan, O.S. and F. Almeida (1988): Geophysical methods as a tool to explore submerged marine archaeological sites, in Marine Archaeology of Indian Ocean Countries, edited by S.R. RAO (Goa, India: National Institute of Oceanography), 3-5.

De Santis, A., L. Gaya-Piqué, G. Dominici, A. Meloni, J.M. TORTA and R. TOZZI (2003): Italian Geomagnetic Reference Field (ITGRF): update for 2000 and secular variation model up to 2005 by autoregressive forecasting, Ann. Geophysics, 46 (3), 491-500.

FAGgioni, O. and F. CARATORI TONTINI (2002): Quantitative evaluation of the time-line reduction performance in high definition marine magnetic surveys, Mar. Geophys. Res., 23, 353-365.

FAgGioni, O., N. BEVERINI and C. CARMisciano (1997): Geomagnetic time variations and high definition study of space magnetic effects induced by artificial submerged sources, Boll. Geofis. Teor. Appl., 38, 915-930.

Ferraccioli, F., M. Gambetta and E. Bozzo (1998): Microlevelling procedures applied to regional aeromagnetic data: an example from the Transantartic Mountains (Antartica), Geophys. Prosp., 46, 177-196. 
MinTY, B.R.S. (1991): Simple micro-levelling for aeromagnetic data, Expl. Geophys., 22, 591-592.

PARKINSON, W.D. and F.W. JonES (1979): The geomagnetic coast effect, Rev. Geophys. Sp. Phys., 17, 1999-2015.

QuinN, R., J.A.G. Cooper and B. Williams (2000): Marine geophysical investigations of the inshore coastal waters of Northern Ireland, Int. J. Naut. Arch., 29, 294-298.

(received September 9, 2005; accepted May 30, 2006) 